\title{
Prevention of early childhood caries
}

Amid I. Ismail

Department of Cariology, Restorative Sciences, and Endodontics, School of Dentistry, The University of Michigan, Ann Arbor, Michigan, USA
Ismail AI: Prevention of early childhood caries. Community Dent Oral Epidemiol 1998; 26: Supplement 1: 49-61. (C) Munksgaard, 1998
Abstract - This paper reviews the methods used for the prevention of early childhood caries (ECC). The education of mothers or caregivers to promote healthy dietary habits in infants has been the main strategy used for the prevention of ECC. This review found that education has a modest impact on the development of ECC. While education should be promoted especially in high risk communities and population groups (low-income families and native populations), it should not be the only preventive strategy of ECC. Early screening for signs of caries development, starting from the first year of life, could identify infants and toddlers who are at risk of developing ECC and assist in providing information to parents about how to promote oral health and prevent the development of tooth decay. High risk children include those with early signs of ECC, poor oral hygiene, limited exposure to fluorides, and frequent exposure to sugary snacks and drinks. These children should be targeted with a professional preventive program that includes fluoride varnish application, fluoridated dentifrices, fluoride supplements, sealants, diet counseling, and chlorhexidine. Prevention of ECC also requires addressing the social and economic factors that face many families where ECC is endemic.
Key words: baby bottle tooth decay; dental caries; early childhood caries; infants; nursing caries; prevention

Amid I. Ismail, Department of Cariology, Restorative Sciences, and Endodontics, School of Dentistry, The University of Michigan, $1011 \mathrm{~N}$. University, D2347, Ann Arbor, Michigan 48109-1078, USA Tel: +1 313-647-9190

Fax: +1 313-936-1597

E-mail: ismailai@umich.edu

Accepted for publication 20 January 1998
Early childhood caries (ECC) is a serious sociobehavioral and dental problem that afflicts infants and toddlers in many communities and populations in the United States (1-3) and in other countries $(4,5)$. The condition is endemic in low-income and native communities in the United States $(6,7)$. This paper presents a summary of the evidence supporting the effectiveness of currently used methods to prevent ECC and briefly discusses the sociopolitical support and changes that are needed to launch successful preventive programs of ECC. Before a discussion of the different preventive strategies of ECC, however, the key issues need to be clarified.

First, recommendations for preventive maneuvers of any disease should be based on scientific studies that have tested the efficacy and effectiveness of the interventions that could be used to prevent a disease. Unfortunately, there have been few well-controlled studies of the prevention of ECC since the last major review of the condition was commissioned in 1988 (8). Because of the paucity of well-designed clinical trials, this review pre- sents a qualitative rather than a quantitative analysis, and is based on a subjective rather than an objective evaluation of the evidence on the prevention of ECC.

Second, maneuvers for the prevention of any disease should be based on a pragmatic, objective, and valid definition of the problem targeted for prevention. The dental community has debated a number of definitions of ECC (9) and has heavily targeted one detrimental habit associated with it: baby bottle use, disregarding other determinants (10). In my opinion, we must strive to prevent the occurrence of any caries activity in infants and toddlers and we need to abandon the debate on the number and location of carious lesions that constitute a dental problem during the early years of life. Instead, I suggest that the appearance of a single carious lesion, in infants and toddlers, on any tooth surface must be considered a serious health problem. Hence, ECC needs to be defined as the occurrence of any sign of dental caries on any tooth surface during the first 3 years of life. 
Third, the prevention of ECC should be based on a comprehensive rather than a restricted understanding of the condition. Early childhood caries has a complex etiology and there are still several unexplained interactions among factors such as infection with mutans streptococci, education status of mothers, dental knowledge, stress, self-esteem, social status, family structure and social networks, and the use of baby bottles or nursing on demand (11). The presence of any one determinant of ECC, such as nursing on demand, may or may not lead to the demineralization of dental enamel and the development of ECC.

\section{Review}

This review is based on information obtained from a literature search of two databases: Medline and the Nutrition Database. The index terms used in the search included: early childhood caries, nursing caries, baby bottle tooth decay, dental caries, infants, toddlers, prevention, effectiveness, education, fluoride, diet, and oral hygiene. Relevant papers published between 1966 and 1997 were identified after a review of the abstracts.

A total of approximately 130 papers were reviewed and abstracted. No well-conducted clinical trial on the prevention of ECC was identified. The Agency for Health Care Policy and Research's guidelines for rating the level of evidence were used in this review (12). Recommendations were reached on the basis of the Canadian Task Force on the Periodic Health Examination classification (Table 1) (13). Recommendations for including or excluding preventive methods are based on the strength of the evidence supporting their effectiveness or lack of it. Recommendation level " $\mathrm{A}$ " is awarded to methods that have consistently been found, in well-conducted randomized clinical trials or controlled prospective studies or meta analyses, to be effective in preventing a disease. Similarly, recommendation level " $E$ " is reserved for methods that have consistently been found to be ineffective. A recommendation level " $\mathrm{C}$ " means that while there is poor evidence to support the inclusion of a preventive method, it is nevertheless recommended because it may have some benefit in the prevention of ECC.

\section{Effectiveness of current preventive methods}

There are three general approaches that have been used to prevent ECC (Fig. 1). The first is a community-based strategy that relies on educating mothers in the hope of influencing their dietary habits as well as those of their infants (8). This approach also includes fluoridating the water supply and personal and community preventive programs in high risk communities. The second approach is based on the provision of examination and preventive care in dental clinics. The third involves the

Table 1. Quality of evidence and classification of recommendations

\begin{tabular}{ll}
\hline Level of evidence & Description \\
\hline I & Well-designed randomized controlled trials \\
II-1a & Well-designed controlled trials with pseudo-randomization \\
II-1b & Well-designed controlled trials with no randomization \\
II-2a & Well-designed cohort (prospective) studies with concurrent controls \\
II-2b & Well-designed cohort (retrospective) studies with concurrent controls \\
II-3 & Well-designed case-control (retrospective) studies \\
III & Large differences from comparisons between times and/or places with and without interventions \\
IV & Opinions of respected authorities based on clinical experience, descriptive studies or reports of expert \\
& committees
\end{tabular}

Recommendations for preventive maneuvers

\begin{tabular}{ll} 
A & There is good evidence to support its inclusion \\
B & There is fair evidence to support its inclusion \\
C & There is poor evidence to support its inclusion but it is still recommended on other grounds \\
D & There is fair evidence to support its exclusion \\
E & There is good evidence to support its exclusion \\
\hline
\end{tabular}

Sources: Agency for Health Care Policy and Research. Manual for conducting systematic reviews. Woolf SH, editor. Rockville (MD): AHCPR; 1996.

Canadian Task Force on Periodic Health Examination. The Canadian guide to clinical preventive health care. Goldbloom RB, editor. Ottawa, Ontario: Minister of Supply and Services Canada; 1994. p. xxxvii. 


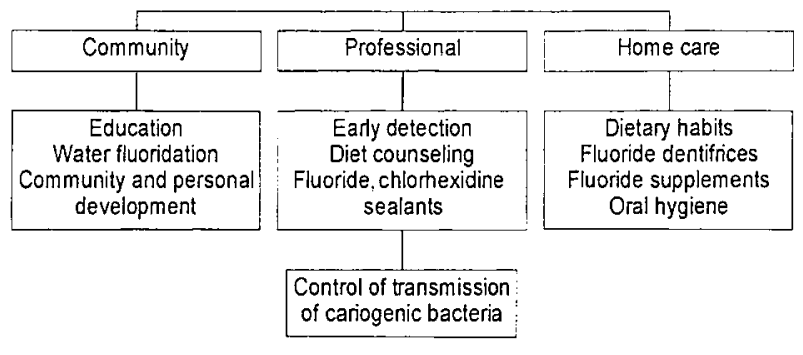

Fig. 1. Strategies for the prevention of ECC.

development of appropriate dietary and self-care habits at home. All three approaches include the education of the mothers or caregivers to follow healthy dietary $\mathrm{a}^{\prime} \mathrm{d}$ feeding habits (to be discussed in the next sections) in order to prevent the development of ECC. Since education is also the most commonly discussed topic in the literature, this review will start by discussing the effectiveness of community-wide educational intervention.

\section{Community-based education}

The goal of education is to increase the knowledge of mothers about ECC, and to improve the dietary and nutritional habits of infants and mothers. It is assumed that an increase in the knowledge of mothers or caregivers will influence their self-care habits and dietary practices and, in turn, improve the dietary and oral hygiene habits of infants leading to the prevention of ECC. While these assumptions are logical, either there is no scientific evidence to support them or the evidence is weak (level III in Table 1).

There is evidence from cross-sectional studies that the education status of parents (a proxy measure of the knowledge level about healthy behaviors) is inversely associated with the prevalence of inappropriate use of the baby bottle, especially at bedtime (14). Education status is also inversely associated with the mean number of decayed, missing and filled (dmft) teeth at the age of 3 years (15). Significantly more mothers of children with ECC lack knowledge about some of the determinants (allowing infants to sleep with the bottle, and time when baby is weaned off the bottle) and prevention of ECC than mothers of children without ECC $(16,17)$. Knowledge about ECC and its prevention could be increased as demonstrated in a recent study where low-income mothers at a Women, Infants, and Children (WIC) clinic who participated in an educational program positively changed their attitudes and knowledge about ECC compared with control mothers (18).
While knowledge is a prerequisite for healthy behaviors, it is not sufficient to influence a change in non-healthy behavior (19). Johnsen (16) found that $40 \%$ of mothers of ECC infants admitted knowing about the potential harmful effects that may result from putting infants to bed with a bottle containing milk or a sugary solution, yet they continued the practice. Other studies confirmed this observation $(20,21)$. The available evidence shows that the current methods used to influence positive oral health behaviors and dietary habits of mothers or caregivers are not very effective in changing those behaviors $(11,19,22,23)$ or influencing dietary practices associated with $\operatorname{ECC}(20,21)$.

Self-esteem is a significant predictor of dental and other health behaviors $(24,25)$. Self-esteem is based upon a judgment of personal worth in society and is influenced by the appraisal of other individuals and society at large (25). Thus self-esteem may explain why one dental health educational program was more successful in "non-deprived" than deprived schools (26) and why an Indian Health Service (IHS) program that attempted to improve self-image, attitudes, and self-esteem of adults participating in an alcohol prevention program decreased the mortality rate from alcoholism by $52 \%$ in 7 years (27).

Positive changes in infant feeding practices have been found to be modest, even when a community educational program was designed and implemented in collaboration with members of a highECC risk community (5). A recent Canadian longitudinal study found an increase in the proportion of mothers who stopped bottle-feeding their infants before the age of 1 year and a modest decrease in the proportion of infants who slept with the bottle (from $57 \%$ in 1992 to $42 \%$ in 1996) compared with mothers from non-participating communities (5). In this Canadian study, the mothers were given handmade cradles traditionally used for comforting infants, and participating communities built "smoke houses" to provide families with smoked meat and fish that were used to comfort fussy infants and toddlers. In addition to these novel approaches the project staff prepared and distributed pamphlets, logos, and posters. Community nurses distributed toothbrushes and toothpaste.

This study confirms the modest behavioral changes observed in a large US demonstration project designed to prevent $\operatorname{ECC}(7,28)$. The study was carried out a decade ago in American Indian and Alaska Native communities. The goal of the study 
was to reduce the number of children with ECC by $50 \%$ in a 5 -year period. The 12 study sites served by the Indian Health Service were divided into three intervention approaches: high, medium, and low intensity. In the high-intensity sites, community coordinators of the project and parent volunteers were trained to administer the educational program on site directly by the project development team. In the medium-intensity sites, the coordinators only attended a training session organized by the development team of the project. In the lowintensity sites, only the project educational material and guidelines were mailed and no training was provided.

The educational program was designed to address the feeding problems identified in the communities: unwillingness of parents to wean children from the bottle, weaning a child to the bottle instead of a cup, and the lack of knowledge about ECC. The program included one-to-one counseling, where volunteers, health professionals and employees from the community discussed ECC and its prevention with mothers or caregivers. The program also included extensive community-based interventions such as "swap parties" where parents were encouraged to exchange their child's bottle for a cup by 1 year of age. The logo used in the project was appropriately labeled "Stop BBTD" (baby bottle tooth decay). It was printed on cups, bumper stickers and coupons. Health professionals (physicians, nurses) and other employees were educated about BBTD and encouraged to participate in the interventions.

After 3 years, there was a 33\% reduction in ECC prevalence in high-intensity sites, $18 \%$ in mediumintensity sites, and $27 \%$ in low-intensity sites. The publicity campaign of the project and the "halo" effect, which may have resulted from promoting its messages in all communities, precludes an evaluation of the effectiveness of the three intensity levels of the program. Nevertheless, the overall reduction was $25 \%$ after 3 years compared to the baseline levels of ECC in the same communities. An 8-year follow-up of the program found a reduction of $38 \%$ in ECC in the five sites that continued to implement the program, and 13\% in the sites that discontinued the program after 3 years. This project has not met its optimistic target of a $50 \%$ reduction in ECC.

What is the message?

Most educational programs targeting mothers or primary caregivers have centered on modifying the use of baby bottle or nursing habits. The previous names of the condition (baby bottle tooth decay, nursing caries) reflect the consistent observation in pediatric dental clinics that infants with ECC frequently use bottles filled with milk or sugary fluids, especially at bedtime. However, not all children with ECC use baby bottles $(7,29)$. A recent case-control study in South Africa found no association between baby bottle use and ECC (30). It must be noted that in this study about $45 \%$ of the children in the control group had other carious lesions that did not match the case definition of nursing caries used to identify the cases (two or more labial or palatal surfaces of the maxillary primary incisors). Hence, there was no true diseasefree control group.

Yet, the current limited evidence points to association between ECC and the frequent feeding of infants with baby foods and drinks that contain sugar, feeding on demand, and most detrimentally, feeding at bedtime or leaving the bottle in the mouth of a sleeping child (31-34). Children who inappropriately use baby bottles are also exposed to frequent sugar intake during the day $(31,34)$, making it difficult to identify, from cross-sectional studies, what sugar source caused ECC. Even with the limited understanding of the complex etiology of ECC, the current knowledge we have about the disease underscores the need to continue to promote healthy feeding practices of infants. Frequent and prolonged use of sugary foods, sleeping with the bottle and using sweets as pacifiers are detrimental habits. Prevention of ECC should also include using fluoride and promoting supervised toothbrushing with a fluoridated dentifrice when the teeth erupt in the mouth.

Who is the message for?

Mothers are the primary promoters of oral hygiene practices $(35,36)$ and they have a major influence on the dietary habits and food choices of infants, toddlers, and children (37-40). There is a moderate correlation $(r=0.3-0.4)$ between infants' carbohydrate and nutrient intakes and that of their mothers $(41,42)$. There is evidence to support that positive changes in oral health status of infants are linked to changes in the oral health behaviors and dietary practices of their mothers. A cross-sectional study in the Netherlands found that a mother's motivation to engage in preventive dental behavior is inversely associated with mean dmfs and DMFS scores of children, and interdental cleaning of mothers was the strongest determinant of interden- 
tal cleaning of infants (odds ratio $=2.4$ ) (43). Hence, it can be concluded that programs designed to prevent ECC must provide support for and involve the participation of the mothers or caregivers.

\section{Recommendation for educational programs}

In conclusion, there is evidence that a modestly positive change can be achieved in the dietary and personal health behaviors of infants at risk of developing ECC. However, this limited success requires a significant investment in community organization and promotion. The cost and resources required to mount a community-based collaborative educational program preclude this approach gaining general usage in high-ECC communities and, given the return on the investment, we need to re-think how and what educational programs are required to prevent ECC. Although the current evidence does not support a wide-scale implementation of educational programs to prevent ECC, there is still a need to provide information to encourage behavioral changes. Education programs could still be recommended for high-ECC risk groups and communities. When programs are appropriately designed they have a short-term positive impact (recommendation level " $\mathrm{C}$ ", Tables 1 and 2).

\section{Water fluoridation}

All infants and toddlers, regardless of their risk status, could benefit from water fluoridation. Water fluoridation has been found to be highly effective $(40-60 \%)$ in a cross-sectional study in preventing dental caries in the primary dentition (44). Further- more, it has been found to be more effective in preventing dental caries in children from low socioeconomic groups than in those from high socioeconomic groups (44). Water fluoridation provides the only means of prevention that does not require a dental visit or parental motivation. Thus there is strong evidence to support water fluoridation in the prevention of dental caries and this preventive method in other reports has received a recommendation level " $A$ " in the prevention of dental caries in primary and permanent teeth (45). However, there is no evidence that water fluoridation has a direct effect on ECC, although the reduction in dental caries in 5-year-old children was reported to be highly significant (44). Accordingly, water fluoridation is recommended at the " $\mathrm{B}$ " level (Tables 1 and 2).

\section{Community and personal development}

The effectiveness of income support and other family assistance programs on the prevention of teenage childbearing, dropping out of school, and other social indicators has not been thoroughly studied and the available data indicate that income support for families has a weak effect on these outcomes (46). Income and education are strong determinants of dental caries in the primary dentition (15) and improvement in these factors may have an impact on the health of infants and toddlers if other social and behavioral factors improve as well (46). Accordingly, community and personal development may have an impact on ECC development and they should receive a recommendation level "C" (Table 2).

Table 2. Recommendations for preventive maneuvers for early childhood caries

\begin{tabular}{lcc}
\hline Interventions & Target & Recommendation* \\
\hline 1. Community and personal development & Community & $\mathrm{C}$ \\
2. Chlorhexidine varnish & High-ECC risk groups & $\mathrm{C}$ \\
3. Dietary counseling & High-ECC risk groups & $\mathrm{C}$ \\
4. Early detection & All infants before the age of 1 year & $\mathrm{C}$ \\
5. Education & All infants and toddlers & $\mathrm{C}$ \\
6. Education & High-ECC risk communities & $\mathrm{C}$ \\
7. Fluoride supplements & High-ECC risk groups & $\mathrm{C}$ \\
8. Fluoride dentifrices & All infants and toddlers & $\mathrm{C}$ \\
9. Fluoride varnish & High-ECC risk groups & $\mathrm{C}$ \\
10. Oral hygiene instruction & All infants and toddlers & $\mathrm{C}$ \\
11. Prenatal fluoride supplements & High-ECC risk groups & $\mathrm{C}$ \\
12. Sealants & Community & $\mathrm{C}$ \\
13. Water fluoridation & High-ECC risk groups & $\mathrm{C}$ \\
14. Xylitol substitutes & High-ECC risk groups & $\mathrm{C}$ \\
15. Control of mother-infant infection with cariogenic bacteria & & \\
\hline
\end{tabular}

* See Table 1. 
Professional and home-based preventive approaches

Some of the professionally applied and homebased approaches that could be employed in the prevention of ECC are listed in Fig. 1 and Table 2. Unfortunately, only a few studies investigated the effectiveness of these preventive strategies early in life (0-3 years of life). It is invalid to extrapolate the results of studies carried out on children with average caries experience to children with high caries experience, and it is equally invalid to extrapolate from studies that were carried out on schoolaged children to infants and toddlers. At the present, we have no information on what professional and home-based preventive approaches could work in preventing carries in young children or even in school-aged children with very high caries activity $(42,47)$. Nonetheless, children from low socioeconomic status families or those living in native communities are at a high risk of developing $\mathrm{ECC}$ and require a more intensive preventive program than low risk children. Additionally, infants with early signs of dental caries, heavy plaque accumulation (48), and high mutans streptococci levels (34) should also be classified at high risk of ECC. In the absence of scientifically validated information, the strategies listed in Fig. 1 should be applied according to the past ECC experience of a family or a community (Fig. 2).

Following the approach suggested in Fig. 2, all infants should receive an early dental examination at or before the age of 1 year as recommended by the American Academy of Pediatric Dentistry (49). Early screening could help in the early identification of incipient carious lesions on smooth tooth surfaces. Additionally, early dental visits provide an opportunity to review feeding and oral hygiene

\section{Early dental examination}

No signs of ECC or

low-ECC risk status

Fluoridated dentifrices

Review of dietary and oral hygiene practices

\begin{tabular}{l}
$\begin{array}{l}\text { Signs of ECC or } \\
\text { high-ECC risk status }\end{array}$ \\
\hline $\begin{array}{l}\text { Fluoridated supplements } \\
\text { and dentifrices }\end{array}$ \\
Dietary counseling \\
Fluoride varnish \\
Sealants \\
Chlorhexidine varnish \\
Xylitol pacifiers
\end{tabular}

Fig. 2. A plan for the prevention of ECC in infants. practices, and plan a program of professional fluoride applications (50).

The first sign of dental caries in infants who develop ECC is the appearance of white demineralization areas in the cervical areas of the maxillary anterior teeth. Such indicators are strongly associated with high caries activity in children $(51,52)$. The prevalence of incipient carious lesions in 6-34month-old infants is about $30 \%$ in high-ECC risk communities (53), and presence of incipient lesions is a good predictor of future caries development (54). Incipient carious lesions progress to cavitation within 6 to 12 months (55). In one study, of the incipient lesions detected at the age 2.5 years, $64 \%$ progressed to cavitation in 1 year (56).

Parents of infants who have no signs of early dental caries and who are not at risk of developing dental caries (do not live in endemic areas or have limited exposure to sugary foods and drinks) should receive information on toothbrushing and use of fluoridated dentifrices. The use of a fluoridated dentifrice is effective in caries prevention (57, 58). The effectiveness of toothbrushing with fluoridated dentifrice depends on the attention and care of the mothers or caregivers (59). In one study with children, a $0.4 \%$ stannous fluoride gel prescribed for home application was terminated after 3 months because of the significant progression of caries (23). While the use of fluoride dentifrices is an important self-care method for the prevention of dental caries, the influence of community-based oral hygiene education on long-term oral hygiene practices is "small and temporary" (19). There is evidence from a longitudinal study that the accumulation of dental plaque on maxillary central incisors in 19-month-old infants is a good predictor of caries development within the next 18 months ( $83 \%$ sensitivity and $92 \%$ specificity) (48). Hence, promotion of early oral hygiene care should be strongly encouraged.

Infants diagnosed with early or advanced signs of dental caries or infants who live in endemic high-ECC areas should receive an intensive preventive program (Table 2). The best current preventive strategy for children susceptible to dental caries is the frequent application of fluoride at home and in dental offices. Fluoride is highly effective in remineralizing enamel and inhibiting the progression of incipient lesions (60). The effective concentration of fluoride is directly dependent on the caries activity (61) and therefore, children with ECC may require more frequent applications of fluoride. Post-eruptive effects of fluoride are now consid- 
ered to be the main mechanism by which fluoride assists in caries prevention (62), and preliminary data suggest that a fluoride concentration in saliva or plaque greater than or equal to $0.9 \mathrm{mg} / \mathrm{L}$ may protect teeth against demineralization even in the presence of a high cariogenic challenge (63).

For professional fluoride applications to children who have early signs of ECC or are in the high risk groups, fluoride varnishes could be used because the compliance of parents in returning to clinics is often poor (55). Fluoride varnishes have been shown to be effective in the permanent dentition (19\% to $57 \%$ reduction) (64), but effectiveness in the primary dentition is lower $(<15 \%)(65,66)$. Fluoride from a varnish has been shown to be released slowly from the subsurface enamel of primary molars (67), and it retards enamel softening following a cariogenic challenge (68).

In addition to benefiting from professional fluoride applications, high risk children or those who live in non-fluoridated communities may benefit from the use of fluoride drops or tablets (69). The current effectiveness of supplements, which is dependent on parents' compliance with a daily regimen, is unknown. Use of fluoride supplements between the ages of 1.5 and 6 years does not protect against dental caries development later on during the teenage years (70). There are also some concerns about the role of supplements in causing fluorosis in the permanent dentition $(70,71)$. Children who regularly brush with a fluoridated dentifrice are the ones most likely to use fluoride supplements (72). The ingestion of fluoridated dentifrice by infants and toddlers also raises concerns about the need for any use of fluoride supplements at that early age (73). However, for infants with high levels of caries, the risk of fluorosis should be weighed against the benefits of a reduction in dental caries incidence.

The use of fluoride supplements requires a high level of commitment from the mothers or caregivers. Unfortunately, for ECC children this strategy may not work because of the social, economic and life dilemmas facing high-ECC risk groups. Moreover, the concept of promoting health through the daily use of a drop or tablet from a "bottle" contradicts the concept that self-care and the adoption of a healthy life style promote health.

The current scientific evidence clearly shows that prenatal fluoride supplements are not beneficial in preventing caries in the primary dentition (74) and therefore should not be prescribed.

In addition to benefiting from the use of fluoride, infants and toddlers at risk of ECC may benefit from the application of pit-and-fissure sealants to their primary molars (75). Long-term data on the effectiveness of newer generations of sealants and glass ionomer cements in preventing dental caries in primary teeth are not yet available. Unfortunately, sealant effectiveness is lower in children with high caries prevalence (76) (>6 dmft [decayed, missing, or filled primary teeth]) than in children with a lower prevalence of dental caries (77). One problem of using sealants in young children is the requirement for moisture control. The use of a dentin-bonding agent between the sealant and the tooth assists in the retention of sealants even when the etched surface is contaminated with saliva (78).

Infants who have plaque-free dentition and use fluoridated toothpaste are less likely to develop dental caries by the age of 3 years (79). These positive oral health behaviors may be indicators of overall healthy dietary and feeding habits and are associated with higher income and education levels. The current evidence does not indicate that dietary counseling or oral hygiene instructions are effective in changing behaviors and preventing ECC $(45,55)$. Nonetheless, for children at risk of developing ECC, advice on appropriate dietary habits and counseling should be conducted regularly.

The high-ECC risk group could benefit from the application of chlorhexidine varnishes. A varnish containing $1 \%$ chlorhexidine and thymol was found to reduce dental caries in the fissures of permanent molars by $50 \%$ in a 2-year clinical trial (80). Trials on another varnish containing $10 \%$ chlorhexidine acetate for the prevention of dental caries is underway in Scotland. Chlorhexidine varnishes may be useful in preventing the transmission of cariogenic bacteria (mutans streptococci) from mothers to infants (81). A chlorhexidine varnish could easily be applied in infants and toddlers and does not require the same level of moisture control as sealants.

Finally, for high-ECC risk infants and toddlers a special pacifier containing fluoride $(0.25 \mathrm{mg})$, xylitol and sorbitol could be efficacious in controlling dental caries (82). Unfortunately, there are no data from clinical trials that test the effectiveness of these pacifiers in high risk infants and toddlers. Xylitol-containing gum is effective in preventing dental caries in primary teeth (83), though it is impractical for use in infants and toddlers. Xylitol promotes the selection of less cariogenic mutans streptococci (84). For infants and toddlers, a paci- 
fier that contains xylitol is a novel idea that could be used as a temporary substitute for feeding at night or bedtime or for a pacifier laced with sugar.

\section{Prevention of transmission of cariogenic bacteria}

There is evidence that cariogenic bacteria (specifically mutans streptococci) are transmitted from mothers to their infants $(85,86)$. Genotypes of mutans streptococci in infants appeared identical to those of the mothers in $71 \%$ of 34 mother-infant pairs (86). An extensive preventive program designed to suppress the transmission of mutans streptococci and prevent dental caries was successful in reducing the infection of infants $(70 \%$ and $41 \%$ of the children in the control and test groups were infected by the age of 3 years, respectively) and in preventing dental caries $(43 \%$ and $16 \%$ of the children in the control and test groups developed caries by the age of 3 years, respectively) (81). This non-randomized study divided mothers who had at least $10^{6}$ mutans streptococci per milliliter of saliva into test and control groups. The test program included provision of dental education, oral hygiene instructions, dental treatment, tooth cleaning, application of $2 \%$ sodium fluoride, fluoride varnish and, if the levels of mutans streptococci remained high, application of $1 \%$ chlorhexidine digluconate gel. The program started when the infants were 3-8 months of age and continued until they reached the age of 3 years. After 4 years, reexamination of 59 children and 58 mothers found that children whose mothers were in the experimental group had a significantly lower mean number of decayed, missing and filled primary teeth (5.2) compared with children of mothers in the control group (8.6) (87).

A recent randomized controlled trial to test the effectiveness of six applications of an iodine-sodium fluoride solution administered to the mothers at the time of tooth eruptions in their infants did not, however, find a significant impact on colonization with mutans streptococci or caries incidence between the treatment and a control groups (88). Additionally, a 3-year longitudinal study testing the effectiveness of a chlorhexidine-fluoride gel treatment in mothers on the establishment of mutans streptococci in primary teeth and development of dental caries in infants found a modest impact on caries incidence in the infants (89). Interestingly, this study confirmed previous findings (81) that infants who were colonized after the age of 3 years had a significantly lower incidence of dental caries (89). Moreover, infants of mothers with low levels of mutans streptococci had a low risk of developing dental caries.

While there is evidence of the effectiveness of an extensive and long-term preventive program targeting mothers with high levels of mutans streptococci, the effectiveness of such an intervention has not been replicated and the costs, compliance, and motivation required in launching a similar program may be prohibitive. Accordingly, a preventive program targeting mothers receives a recommendation " $\mathrm{C}$ " (Table 1 ).

\section{Conclusions}

At the present there are only limited long-term data on effectiveness and feasibility methods to prevent ECC. In the absence of good scientific data for this age group, the only option we have is to use the tools that have been found effective in other age groups. A preventive strategy for children at risk of developing ECC is therefore recommended; however, the main determinant of success is the motivation of the mother or caregiver to follow self-care instructions and bring a child to a clinic for preventive care (53).

\section{Discussion}

Early childhood caries is a social, political, behavioral, medical and dental problem that can only be controlled through understanding the dynamic changes that are taking place in society particularly as they pertain to family structure, nurturing of children and socioeconomic status. ECC is a social problem because it clusters in the disadvantaged members of society. With the increase in polarization of society into two strata, rich and poor, the prevalence of social problems increases (46). ECC is a political problem because its solution involves changing and reorganizing values and political priorities. Childhood diseases, hunger, education, family support, parents' employment, and low selfesteem are some of the many problems facing families where ECC is endemic. ECC is a behavioral problem because it involves daily actions (or lack of action) by mothers, nannies, grandparents, caregivers, and foster families, among others. Oral health, especially involving baby teeth, is not a priority to many who live in poverty or who do not have a secure environment. ECC is a medical problem because infants with early childhood caries continue to grow at a slower pace compared with caries-free infants (90). Children born after mater- 
nal complications during pregnancy or who have had traumatic births are at risk of developing ECC (91). Children with early childhood caries most often require costly dental treatment in a hospital under sedation or general anesthesia (92).

\section{New approaches}

The prevention of ECC should not be based on one approach because there is no scientific evidence to favor one approach over another. Moreover, our understanding of the development of ECC is still incomplete. Hence, whole-population approaches $(47,93)$ that would disseminate information on ECC and its prevention based on current etiological paradigms of this disease are required. This dissemination should occur through the local media, community education programs, prenatal and postnatal classes, maternity clinics, and schools. An active promotion of water fluoridation could provide a cost-effective preventive method especially for children from low socioeconomic groups (44). Additionally, programs that improve self-image and self-esteem may be of value. There is circumstantial evidence that such an approach succeeds in combating chronic social problems like alcoholism in native communities (27).

Both strategies could be implemented via the development of "Early Head Start Community Centers" (Fig. 3) in disadvantaged communities. In these proposed comprehensive community centers, mothers and infants would not only receive medical and dental care but also receive prenatal and postnatal counseling, nutritional and dietary counseling, early screenings, job training and employment skills, education in early prevention, as well as health care and WIC services. The centers would assist families in high risk communities in promoting their own social, mental, and physical health.

The proposed Early Head Start Community Centers could be organized in collaboration with communities, academic institutions, private industry,

Early Head Start Community Center

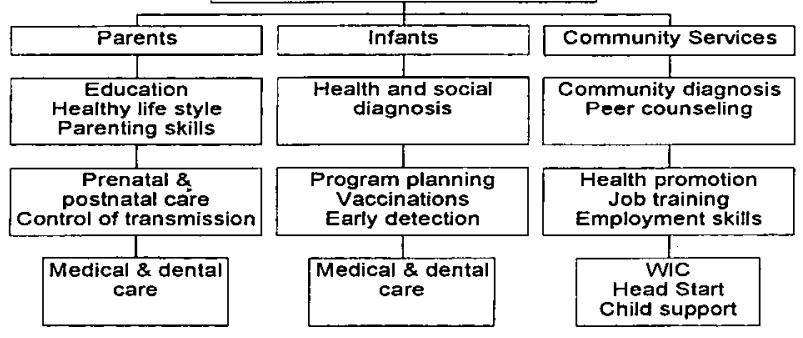

Fig. 3. An integrated model for the prevention of ECC. and health organizations (94). The centers would provide primary health care using nurse practitioners (95), nutritionists, social workers, physicians, dentists and dental hygienists (95). The clinics will also be the base for WIC staff and Head Start staff. Dental education and prevention activities in high risk communities could be integrated with other medical, social, nutritional, and welfare programs. Currently, other than past dental caries experience, there are no good predictors of dental caries that can be applied in dental practices (47). High risk status could be defined as (a) past caries experience of a community or population group, (b) the identification of early signs of dental caries in infants and toddlers, (c) evidence of poor oral hygiene, and (d) inappropriate dietary habits.

Currently, there is a small federal program entitled "Early Head Start" that aims to enhance children's physical, social, emotional and cognitive development; enable parents to be better caregivers and teachers of their children; and help parents meet their own goals, including that of economic development. In FY 1995, USD 47.2 million were spent on Early Head Start programs for 5000 children and in FY 1996 spending increased to USD 143 million. The new program is still in its infancy, and lobbying should be planned to incorporate all health, nutrition, education, and self-development programs for mothers and infants (Zero-to-Three Years). Early Head Start is an excellent program to build upon to establish the proposed Early Head Start Community Centers to integrate and focus all services for mothers and infants in high risk communities.

While some may argue that there can be no funding for new programs in this era of budget cuts, the long-term social and economic costs of child poverty and disease could have severe detrimental impact on the future of any society in this world. We need to investigate the effectiveness of the current welfare programs and create new programs that promote self-reliance, assist in child development, and assist children in their social, mental, physical, and educational development.

\section{Barriers to the prevention of ECC}

Any proposal to improve the social, mental, and physical health of children cannot be successful without adequate funding and support. Success cannot be achieved in the absence of political leadership involving all levels of government, dental organizations, and communities to remove poten- 
tial barriers (96). These potential barriers are as follows.

First, there is a lack of involvement and commitment from many dental and other health organizations. The American Association of Public Health Dentistry, the American Association of Public Health, the Centers for Disease Control and Prevention and the American Academy of Pediatric Dentistry are the main organizations that have led most of the discussion on the problem of ECC. Other dental and non-dental organizations have not been active in this issue. There has been no lobbying for new initiatives in planning, developing or funding new programs by organized dentistry to combat ECC in high risk communities. Organizing one meeting every other year to talk about ECC is not enough.

Second, the dental community lacks a shared vision of the definition of the problem, how to prevent it and who is responsible for planning and

Table 3. Non-government organizations (NGO) serving American children

American Public Welfare Association

Center for Career Development in Early Care and Education Child Care Action Campaign

Child Care Law Center

Children's Defense Fund

Children's Foundation

Child Welfare League of America, Inc.

Council of Chief State School Officers

Ecumenical Child Care Network

ERIC Clearinghouse on Elementary and Early Childhood Education

Families and Work Institute

National Association for the Education of Young Children

National Association for Family Child Care

National Association of Child Care Professionals

National Association of Child Care Resource and Referral Agencies

National Black Child Development Institute

National Center for Children in Poverty

National Center for the Early Childhood Work Force

National Child Care Association

National Head Start Association

National Indian Child Care Association

National Resource Center for Health and Safety in Child Care

National School-Age Care Alliance

School-Age Child Care Project

USA Child Care

Women's Bureau, U.S. Department of Labor

Zero-to-Three: National Center for Infants, Toddlers, and Families

Interagency Task Force on Child Abuse and Neglect Clearinghouse Consortium Members implementation. Neither do we have a political advocacy group to inform political leaders about the seriousness of the problem of ECC in some communities. The community at large and other health professionals do not recognize ECC as an important problem facing some children.

Third, there is no integrated plan to fight the social, health, nutritional, and economic issues facing low-income families. The problem is not that we do not have enough money to spend on education and health programs, but rather whether we are allocating the current resources efficiently.

Fourth, as evident from this review and as was identified by Ripa in 1988 (8), there is weak direct support for research on the epidemiology, etiology, prevention and treatment of ECC. The major funding agency in the United States, the National Institute of Dental Research, has not directed resources to promote research of this disease. In the absence of scientific data, we tend to rely on experience and logic, and in the process make wrong choices.

Fifth, dental health is not a priority for most of the federal programs (except perhaps the IHS) that provide services to the populations most susceptible to ECC. The strategic plan for the period for 1997 to 2002 of the US Department of Agriculture does not have any dental indicator in its list of performance measures (infant mortality, incidence of low birth weight, anemia in children and pregnant women, and immunization).

Sixth, the current dental work force is restricted in its ability to provide care for low-income Americans because of limited accessibility to high risk communities, high debt ratio among new dental graduates, restrictive dental practice acts and regulations, and low reimbursement for dental care covered by Medicaid. The current regulations for dental practice in many states restrict the planning of cost-effective alternatives for providing dental care in areas that have endemic levels of ECC and a severe shortage of dental personnel. There also is a need to recruit other health care providers and expand roles for dental hygienists in high-ECC risk communities.

\section{Conclusion}

The evidence presented indicates that, at the moment, there is a lack of effective methods to prevent ECC. Educational interventions have had weak to modest success and professional and home-based interventions have not been tested sufficiently in young populations. It is critical that additional re- 
search is performed in ECC preventive strategies as well as its etiology and epidemiology. Given the complexity of factors associated with ECC, it is unfortunate that most of the interest has only been from dental organizations. The critical change needed to accomplish the necessary research into the prevention of ECC is to expand our network to include other health professionals, community leaders, national organizations serving children, and political leaders (Table 3).

\section{References}

1. Kelly M, Bruerd B. The prevalence of baby bottle tooth decay among two native American populations. J Public Health Dent 1987;47:94-7.

2. O'Sullivan DM, Douglass JM, Champany R, Eberling S, Tetrev S, Tinanoff N. Dental caries prevalence and treatment among Navajo preschool children. J Public Health Dent 1994;54:139-44.

3. Tsubouchi J, Tsubouchi M, Maynard RJ, Domoto PK, Weinstein P. A study of dental caries and risk factors among Native American infants. J Dent Child 1995;62:283-7.

4. Holm A-K. Caries in the preschool child: international trends. J Dent 1990;18:291-5.

5. Harrison R, White L. A community-based approach to infant and child oral health promotion in a British Columbia first nations community. Can J Community Dent 1997;12:7-14.

6. Broderick E, Marby J, Robertson D, Thompson J. Baby bottle tooth decay in Native American children in Head Start Centers. Public Health Rep 1989;104:50-4.

7. Bruerd B, Jones C. Preventing baby bottle tooth decay: eight-year results. Public Health Rep 1996;111:63-5.

8. Ripa LW. Nursing caries: a comprehensive review. Pediatr Dent 1988;10:268-82.

9. Kaste LM, Marianos D, Chang R, Phipps KR. The assessment of nursing caries and its relationship to high caries in the permanent dentition. J Public Health Dent 1992;52:64-8.

10. Navia JM. Guest editorial: caries prevention in infants and young children: which etiologic factors should we address? J Public Health Dent 1994;54:195-6.

11. Litt MD, Reisine S, Tinanoff N. Multidimensional causal model of dental caries development in low-income preschool children. Public Health Rep 1995;110:607-17.

12. Agency for Health Care Policy and Research. Woolf SH, editor. Manual for conducting systematic reviews. Rockville (MD): AHCPR; 1992.

13. Woolf SH, Battista RN, Anderson GM, Logan AG, Wang EEL, Dingle JL. Methodology. In: Goldboom RB, editor. Canadian Task Force on Periodic Health Examination. The Canadian guide to clinical preventive health care. Ottawa, Ontario: Minister of Supply and Services Canada; 1994. p. xxv-xxxviii.

14. Kaste LM, Gift HC. Inappropriate infant bottle feeding. Status of the healthy people 2000 objective. Arch Pediatr Adolesc Med 1995;149:786-91.

15. Tang JMW, Altman DS, Robertson DC, O'Sullivan DM, Douglass JM, Tinanoff N. Dental caries prevalence and treatment levels in Arizona preschool children. Public Health Rep 1997;112:65-75.
16. Johnsen DC. Characteristics and backgrounds of children with nursing caries. Pediatr Dent 1982;4:218-24.

17. Febres C, Echeverri EA, Keene HJ. Parental awareness, habits, and social factors and their relationship to baby bottle tooth decay. Pediatr Dent 1997;19:22-7.

18. Kanellis MJ, Logan HL, Jakobsen J. Changes in maternal attitudes toward baby bottle tooth decay. Pediatr Dent 1997;19:56-60.

19. Kay EJ, Locker D. Is dental health education effective? A systematic review of current evidence. Community Dent Oral Epidemiol 1996;24:231-5.

20. Weinstein P, Domoto P, Wohlers K, Koday M. MexicanAmerican parents with children at risk for baby bottle tooth decay: pilot study at a migrant farmworkers clinic. J Dent Child 1992;59:376-88.

21. Reisine S, Litt M. Social and psychological theories and their use for dental practice. Int Dent J 1993;43:279-87.

22. Phillips MG, Stubbs PE. Head Start combats baby bottle tooth decay. Child Today 1987;16:25-8.

23. Benitez C, O'Sullivan D, Tinanoff N. Effect of a preventive approach for the treatment of nursing bottle caries. J Dent Child 1994;61:46-9.

24. Macgregor IDM, Balding JW. Self-esteem as a predictor of toothbrushing behaviour in young adolescents. J Clin Periodontol 1991;18:312-6.

25. Regis D, Macgregor IDM, Balding JW. Differential prediction of dental health behaviour by self-esteem and health locus of control in young adolescents. J Clin Periodontol 1994;21:7-12.

26. Schou L, Wright C. Does dental health education affect inequalities in dental health? Community Dent Health 1994;11:97-100.

27. Rhoades ER, Mason RD, Eddy P, Smith EM, Burns TR The Indian Health Service approach to alcoholism among American Indians and Alaska Natives. Public Health Rep 1988;103:621-7.

28. Bruerd B, Kinney MB, Bothwell E. Preventing baby bottle tooth decay in American Indian and Alaska Native communities: a model for planning. Public Health Rep 1989;104:631-40.

29. Matee M, van't Hof M, Maselle SY, Mikx FHM, van Palenstein Helderman WH. Nursing caries, linear hypoplasia, and nursing and weaning habits in Tanzanian infants. Community Dent Oral Epidemiol 1994;22:28993.

30. Roberts GJ, Cleaton-Jones PE, Fatti P, Richardson BD, Sinwel RE, Hargreaves A, et al. Patterns of breast and bottle feeding and their association with dental caries in 1- to 4-year-old South African children. 2. A case control study of children with nursing caries. Community Dent Health 1994;11:38-41.

31. Eronat N, Eden E. A comparative study of some influencing factors of rampant or nursing caries in preschool children. J Clin Pediatr Dent 1992;16:275-9.

32. Schwartz SS, Rosivack RG, Michelotti P. A child's sleeping habit as a cause of nursing caries. J Dent Child 1993;60:22-5.

33. Al-Dashti AA, Williams SA, Curzon MEJ. Breast feeding, bottle feeding and dental caries in Kuwait, a country with low-fluoride levels in the water supply. Community Dent Health 1995;12:42-7.

34. Grindefjord M, Dahlof, Nilsson B, Modeer T. Stepwise prediction of dental caries in children up to 3.5 years of age. Caries Res 1996;30:256-66.

35. Levy SM, Maurice TJ, Jakobsen JR. Feeding patterns, water sources and fluoride exposures of infants and 1year-olds. J Am Dent Assoc 1993;124:65-9. 
36. Paunio P. Dental health habits of young families from Southwestern Finland. Community Dent Oral Epidemiol 1994;33:36-40.

37. Johnsen DC, Schultz DW, Schubot DB, Easley MW. Caries patterns in Head Start children in a fluoridated community. J Public Health Dent 1984;44:61-6.

38. Silver DH. A longitudinal study of infant feeding practice, diet and caries, related to social class in children aged 3 and 8-10 years. Br Dent J 1987;163:296-300.

39. Rossow I, Kjaernes U, Holst D. Patterns of sugar consumption in early childhood. Community Dent Oral Epidemiol 1990;18:12-6.

40. Stein A, Stein J, Walters EA, Fairburn CG. Eating habits and attitudes among mothers of children with feeding disorders. Br Med J 1995;310:228.

41. Holm A-K. Education and diet in the prevention of caries in the preschool child. J Dent 1990;18:308-14.

42. Olivier M, Brodeur J-M, Simard PL. Efficacy of APF treatments without prior toothcleaning targeted to high-risk children. Community Dent Oral Epidemiol 1992;20:3842.

43. Rossow I. Intrafamily influences on health behavior. A study of interdental cleaning behavior. J Clin Periodontol 1992;19:774-8.

44. Evans DJ, Rugg-Gunn AJ, Tabari ED, Butler T. The effect of fluoridation and social class on caries experience in 5year-old Newcastle children in 1994 compared with results over the previous 18 years. Community Dent Health 1996;13:5-10.

45. Lewis, DW, Ismail AI. Periodic health examination, 1993 update: Dental caries: diagnosis and prevention. Can Med Assoc J 1994;152:836-46.

46. Mayer S. What money can't buy. Cambridge (MA): Harvard Univ Pr; 1997. pp. 42, 131, 114-24.

47. Hausen H. Caries prediction - state of the art. Community Dent Oral Epidemiol 1997;25:7-96.

48. Alaluusua S, Mamivirta R. Early plaque accumulation a sign for caries in young children. Community Dent Oral Epidemiol 1994;22:273-6.

49. American Academy of Pediatric Dentistry. Infant oral health care. Pediatr Dent 1996;18:25

50. Nowak AJ. Rationale for the timing of the first oral evalution. Pediatr Dent 1997;19:8-11.

51. Steiner M, Helfenstein U, Marthaler TM. Dental predictors of high caries increment in children. J Dent Res 1992;71:1926-33.

52. Lith A, Grondal H-G. Prediciting development of approximal dentin lesions by means of past caries experience. Community Dent Oral Epidemiol 1992;20:25-9.

53. Domoto P, Weinstein P, Leroux B, Koday M, Ogura S, Iatridi-Roberson I. White-spot caries in Mexican-American toddlers and parental preference for various strategies. J Dent Child 1994;61:342-6.

54. Helfenstein U, Steiner M, Marthaler TM. Caries prediction on the basis of past caries including precavity lesions. Caries Res 1991;25:372-6.

55. Weinstein $P$, Domoto $P$, Koday M, Leroux B. Results of a promising open trial to prevent baby bottle tooth decay: a fluoride varnish study. J Dent Child 1994;61:338-41.

56. Grindefjord M, Dahlof, Modeer T. Caries development in children from 2.5 to 3.5 years of age: a longitudinal study. Caries Res 1995;29:449-54.

57. Stamm JW. The value of dentifrices and mouthrinses in caries prevention. Int Dent J 1993;43:517-27.

58. O'Mullane DM. Introduction and rationale for the use of fluoride for caries prevention. Int Dent J 1994;44:257-61.
59. Karjalainen S, Eriksson A-L, Ruokola M, Toivonen A. Caries development after substitution of supervised fluoride rinses and toothbrushings by unsupervised use of fluoride toothpaste. Community Dent Oral Epidemiol 1994;22:421-24.

60. Margolis HC, Moreno EC, Murphy BJ. Effect of low levels of fluoride in solution on enamel demineralization in vitro. J Dent Res 1986;65:23-9.

61. Lammers PC, Borggreven JMPM, Driessens FCM. Influence of fluoride and $\mathrm{pH}$ on in vitro remineralization of bovine enamel. Caries Res 1992;26:8-13.

62. ten Cate JM, Featherstone JDB. Physicochemical aspects of fluoride-enamel interactions. In: Fejerskov O, Ekstrand J, Burt BA, editors. Fluoride in dentistry. Copenhagen, Denmark: Munksgaard; 1996. p. 252-72.

63. Featherstone JDB. Clinical implications: new strategies for caries prevention. In: Stookey GK, editor. Early detection of dental caries. Indianapolis (ID): Indiana Univ Pr; 1996. p. 287-95.

64. Helfenstein U, Steiner M. Fluoride varnishes (Duraphat): A meta-analysis. Community Dent Oral Epidemiol 1994;22:1-5.

65. Grodzka K, Augustyniak L, Budny J, Czarnocka K, Janicha J, Mlosek K, et al. Caries increment in primary teeth after application of Duraphat fluoride varnish. Community Dent Oral Epidemiol 1982;10:55-9.

66. Clark DC, Stamm JW, Quee TC, Robert G. Results of the Sherbrooke-Lac Megantic fluoride varnish study after 20 months. Community Dent Oral Epidemiol 1985;13:61-4.

67. Peyron M, Matsson L, Birkhed D. Progression of approximal caries in primary molars and the effect of Duraphat treatment. Scand J Dent Res 1992;100:314-8.

68. Sorvari R, Spets-Happonen S, Luoma H. Efficacy of chlorhexidine solution with fluoride varnishing in preventing enamel softening by Streptococcus mutans in an artificial mouth. Scand J Dent Res 1994;102:206-9.

69. American Dental Association. Preventive intervention strategies. J Am Dent Assoc 1995;126:19S.

70. Kalsbeek H, Verrips GH, Backer Dirks O. Use of fluoride tablets and effect on prevalence of dental caries and dental fluorosis. Community Dent Oral Epidemiol 1992;20:241-5.

71. Ismail AI. Fluoride supplements: current effectiveness, side effects, and recommendations. Community Dent Oral Epidemiol 1994;22:164-72.

72. Paunio P, Rautava P, Sillanpaa M, Kaleva O. Dental health habits of 3-year-old Finnish children. Community Dent Oral Epidemiol 1993;21:4-7.

73. Levy SM, Kiritsy MC, Slager SL, Warren JJ, Kohout FJ. Patterns of fluoride dentifrice use among infants. Pediatr Dent 1997;19:50-5.

74. Leverett DH, Adair SM, Vaughan BW, Proskin HM, Moss ME. Randomized clinical trial of the effect of prenatal fluoride supplements in preventing dental caries. Caries Res 1997;31:174-9.

75. Weintraub J. The effectiveness of pit and fissures sealants. J Public Health Dent 1989; 49(Spec Iss):317-30.

76. Bravo M, Osorio E, Garcia-Anllo I, Llodra JC, Baca P. The influence of $\mathrm{dft}$ index on sealant success: a 48 -month survival analysis. J Dent Res 1996;75:768-74.

77. Raadal M, Laegreid O, Laegreid KV, Hveem H, Korsgaard EK, Wangen K. Fissure sealing of permanent first molars in children receiving a high standard of prophylactic care. Community Dent Oral Epidemiol 1984;12:65-68.

78. Feigal RJ, Hitt J, Splieth C. Retaining sealant on salivary contaminated enamel. J Am Dent Assoc 1993;124:88-97. 
79. Wendt L-K, Hallonsten A-L, Koch G, Birkhed D. Oral hygiene in relation to caries development and immigrant status in infants and toddlers. Swed Dent J 1994;102:26973.

80. Bratthall D, Serinirach R, Rapisuwon S, Kuratana M, Luangjarmekorn $\mathrm{V}$, Laksila $\mathrm{K}$, et al. A study into the prevention of fissure caries using an antimicrobial varnish. Int Dent J 1995;45:245-54.

81. Kohler B, Andreen I, Jonsson B. The effect of caries-preventive measures in mothers on dental caries and the oral presence of the bacteria Streptococcus mutans and lactobacilli in their children. Arch Oral Biol 1984;29:879-83.

82. Suhonen J, Aaltonen AS, Tenovuo J. Prevention of caries from 2 to 3.5 years of age in children after having used a prophylactic lozenge in a slow release pacifier at bed time. J Dent Res 1997;76(Spec Iss):337.

83. Makinen KK, Hujoel PP, Bennett CA, Isotupa KP, Makinen $\mathrm{P}-\mathrm{L}$, Allen $\mathrm{P}$. Polyol chewing gums and caries rates in primary dentition: a 24-month cohort study. Caries Res 1996;30:408-17.

84. Trahan L, Bourgeau G, Breton R. Emergence of multiple xylitol-resistant (fructose PTS-) mutants from human isolates of mutans streptococci during growth on dietary sugars in the presence of xylitol. J Dent Res 1996;75:1892900.

85. Caufield PW, Cutter GR, Dasanayake AP. Initial acquisition of mutans streptococci by infants: evidence for a discrete window of infectivity. J Dent Res 1993;72:37-45.

86. Li Y, Caufield PW. The fidelity of initial acquisition of mutans streptococci by infants from their mothers. J Dent Res 1995;74:681-5.

87. Kohler B, Andreen I. Influence of caries-preventive measures in mothers on cariogenic bacteria and caries experience in their children. Arch Oral Biol 1994;39:907-11.
88. Dasanayake AP, Caufield PW, Cutter GR, Stiles HM. Transmission of mutans streptococci to infants following short term application of an iodine- $\mathrm{NaF}$ solution to mothers' dentition. Community Dent Oral Epidemiol 1993;21:136-42.

89. Tenovuo J, Hakkinen P, Paunio P, Emilson CG. Effects of chlorhexidine-fluoride gel treatments in mothers on the establishment of mutans streptococci in primary teeth and the development of dental caries in children. Caries Res 1992;26:275-80.

90. Acs G, Lodolini G, Kaminsky S, Cisneros GJ. Effect of nursing caries on body weight in a pediatric population. Pediatr Dent 1992;14:302-5.

91. Peretz B, Kafka I. Baby bottle tooth decay and complications during pregnancy and delivery. Pediatr Dent 1997;19:34-6.

92. Milnes AR, Rubin CW, Karpa M, Tate R. A retrospective analysis of the costs associated with the treatment of nursing caries in a remote Canadian aboriginal preschool population. Community Dent Oral Epidemiol 1993;21:253-60.

93. Batchelor PA, Sgan-Cohen HD, Sheiham A. Strategies for preventing dental caries. Isr J Dent Sci 1990;2:254-70.

94. Sumaya CV. Oral health for all: the HRSA perspective. J Public Health Dent 1996;56:35-46.

95. Stevenson LJ, Coody DK, Evans KD, Plumb SC, Montgomery DF, Yetman RJ. Providing better access to health care: a pediatric nurse practitioner WIC-based clinic for one-stop health care. J Pediatr Health Care 1994;8:16872.

96. Berman PA, Gwatkin DR, Burger SE. Community-based health workers: head start or false start towards health for all? Soc Sci Med 1987;25:443-59. 